\title{
Three-dimensional Alignment of the Upper Extremity in the Standing Neutral Position in Healthy Subjects
}

\section{Yuki Yoshida ( $\nabla$ yuutree.yysy@gmail.com )}

Keio University - Shinanomachi Campus: Keio Gijuku Daigaku - Shinanomachi Campus https://orcid.org/0000-0002-0185-7554

\section{Noboru Matsumura}

Keio University - Shinanomachi Campus: Keio Gijuku Daigaku - Shinanomachi Campus https://orcid.org/0000-0001-7629-0241

\section{Yoshitake Yamada}

Keio University - Shinanomachi Campus: Keio Gijuku Daigaku - Shinanomachi Campus

\section{Satoshi Hiraga}

Keio University - Shinanomachi Campus: Keio Gijuku Daigaku - Shinanomachi Campus

\section{Kazunori Ishii}

Keio University - Shinanomachi Campus: Keio Gijuku Daigaku - Shinanomachi Campus

\section{Satoshi Oki}

Keio University - Shinanomachi Campus: Keio Gijuku Daigaku - Shinanomachi Campus

\section{Yoichi Yokoyama}

Keio University - Shinanomachi Campus: Keio Gijuku Daigaku - Shinanomachi Campus

Minoru Yamada

Keio University - Shinanomachi Campus: Keio Gijuku Daigaku - Shinanomachi Campus

\section{Masaya Nakamura}

Keio University - Shinanomachi Campus: Keio Gijuku Daigaku - Shinanomachi Campus

\section{Takeo Nagura}

Keio University - Shinanomachi Campus: Keio Gijuku Daigaku - Shinanomachi Campus

\section{Masahiro Jinzaki}

Keio University - Shinanomachi Campus: Keio Gijuku Daigaku - Shinanomachi Campus

\section{Research Article}

Keywords: neutral posture, shoulder, elbow, scapulothoracic joint, glenohumeral joint, upright computed tomography

Posted Date: January 6th, 2022 
DOI: https://doi.org/10.21203/rs.3.rs-1182767/v1

License: (c) (1) This work is licensed under a Creative Commons Attribution 4.0 International License. Read Full License

Version of Record: A version of this preprint was published at Journal of Orthopaedic Surgery and Research on April 15th, 2022. See the published version at https://doi.org/10.1186/s13018-022-03113-5. 


\section{Abstract}

Background. Though alignment of the spine and lower extremities in the standing neutral position has been evaluated, a few studies evaluating the alignment of the upper extremities have also been made. This study assessed the normal alignment of the upper extremities in the standing neutral position and clarified the three-dimensional angular rotations of the upper extremity joints.

Methods. Computed tomography (CT) images of 158 upper extremities from 79 healthy volunteers were prospectively acquired in the standing neutral position using an upright CT scanner. Three-dimensional coordinate systems of the thorax, scapula, humerus, and forearm were designated, and three-dimensional angular rotations of the scapulothoracic, glenohumeral, and elbow joints were calculated.

Results. The mean angle of the scapulothoracic joint was $8.5^{\circ} \pm 5.9^{\circ}$ of upward rotation, $28.7^{\circ} \pm 5.9^{\circ}$ of internal rotation, and $7.9^{\circ} \pm 5.2^{\circ}$ of anterior inclination. The mean angle of the glenohumeral joint was $4.4^{\circ} \pm 5.9^{\circ}$ of abduction, $9.4^{\circ} \pm 12.3^{\circ}$ of internal rotation, and $0.3^{\circ} \pm 4.4^{\circ}$ of extension. The mean angle of the elbow joint was $9.6^{\circ} \pm 3.7^{\circ}$ of valgus, $88.8^{\circ} \pm 14.3^{\circ}$ of pronation, and $15.4^{\circ} \pm 4.2^{\circ}$ of flexion.

Correlations in angular rotation values were found, and interactions for keeping the upper extremities in a neutral position were observed.

Conclusions. This study clarified the three-dimensional angular rotation of upper extremity joints in the standing neutral position using an upright CT scanner. Our results may provide important insights for the functional evaluation of upper extremity alignment.

\section{Background}

Human posture is generally viewed as the coordination among the parts of the human body in the standing neutral position. The neutral standing position of the human body is described according to the following alignment: the frontal view is symmetrical; from the lateral view, a perpendicular line begins at the mastoid process of the temporal bone and runs vertically through the acromion, lumbar vertebral bodies, and greater trochanter (slightly posterior to the hip axis and slightly anterior to the knee axis) and ends at the lateral malleolus or slightly anterior to it [1]. The course of this line in normal neutral standing position overlaps the baseline between the center of gravity and the center point of the support [1,2]. On the other hand, the neutral position of the upper extremities is defined as the arms resting at the side with the shoulders in neutral rotation and the palms aligned with the body trunk. This position has been regarded as the standard upper extremity position in previous motion analyses [3-5] and radiographic imaging studies $[6,7]$.

It is clinically useful to understand the alignment of the standing neutral position and numerous studies have investigated the neutral position of loaded joints, such as the spine and the lower extremities [8-10]. However, a few studies have evaluated the neutral posture of the upper extremities, those have assessed only the scapula position $[11,12]$. In addition, the evaluation was performed on the skin and might not accurately capture the 3D position of the bone. In assessing bone position, there have been studies on the 
sagittal alignment of whole axial skeletons using radiographs [13], although the upper extremities in the sagittal plane cannot be evaluated due to overlapping into the trunk of the arms when placed in the hands-on-cheeks position. Conventional CT that allows for accurate 3D bone assessment could only be conducted in the supine position. To the best of our knowledge, no detailed study has evaluated the threedimensional (3D) alignment of the upper extremities in the standing neutral position.

Recently, an upright computed tomography (CT) scanner, whose physical characteristics are comparable to those of a conventional CT machine, has been developed and enables 3D whole-torso cross-sectional scanning in the standing position [14]. We hypothesized that interactions of the upper extremity joints are employed to maintain a neutral position, just as they are employed in the spine and lower extremities. The purpose of this study was to evaluate normal alignment of the upper extremities in the standing neutral position using the upright CT scanner and to clarify the 3D angular rotation of upper extremity joints and their interactions.

\section{Methods}

\section{Participants}

This prospective study was approved by the institutional review board of Keio University School of Medicine, and written consent was obtained from all the participants (study protocol: \#20160384). All experiments were performed in accordance with relevant guidelines and regulations. The prospective subjects included 108 healthy Japanese volunteers with no past illnesses or injuries to the upper extremities, aged between 30 and 60 years. All provided informed consent and agreed to participate in this study and undergo upright CT (prototype TSX-401R; Canon Medical Systems Corporation, Otawara, Japan) $[15,16]$. Twenty-three participants were excluded because their distal humeri were out of the range of the CT images. In addition, six participants were excluded because of asymptomatic scoliosis. Thus, CT images of 158 upper extremities from 79 healthy volunteers ( 25 male and 54 female) were included in the analysis. The mean ( \pm standard deviation) age, height, body weight, and body mass index of the subjects were $44.4 \pm 7.3$ years (range, $30-58$ years), $161.6 \pm 8.3 \mathrm{~cm}$ (range, $147.7-182.1 \mathrm{~cm}$ ), 56.3 $\pm 8.6 \mathrm{~kg}$ (range, $37.8-79.4 \mathrm{~kg}$ ), and $21.5 \pm 2.8 \mathrm{~kg} / \mathrm{m}^{2}$ (range, $15.7-29.2 \mathrm{~kg} / \mathrm{m}^{2}$ ), respectively.

\section{Image acquisition}

The CT images acquired were taken from neck to pelvis using an upright CT scanner in the standing neutral position (Fig. 1). During acquisition, the volunteers were instructed to stand in the relaxed neutral position: spreading their legs according to their shoulder width and touching their sacrum to the pole behind them to keep their body trunk perpendicular to the ground to achieve a safe scanning condition. The upper extremities were positioned with the palms touching the lateral sides of the thighs in a comfortable resting position, defined as the neutral position. Scanning was performed at 100 or $120 \mathrm{kVp}$ and at a gantry rotation speed of $0.5 \mathrm{~s}$ in the helical scan mode (80-detector row) with a noise index of 24 or 15 and helical pitch of 0.8 for the body trunk. Image reconstruction was performed using Adaptive Iterative Dose Reduction in 3D (Canon Medical Systems Corporation, Otawara, Japan), which could 
reduce imaging radiation [17]. The CT data were accumulated in Digital Imaging and Communication in Medicine (DICOM) data format.

\section{Identification of bony landmarks}

Three-dimensional bone surface models of the trunk and upper extremities were segmented from the DICOM data using AVIZO software (version 9.3.0; Thermo Fisher Scientific, Tokyo, Japan) and exported as Standard Triangulated Language (STL) data (Fig. 2) as previously described [18, 19]. The bony landmarks determined according to the International Society of Biomechanics (ISB) recommendations [20] were identified on STL data of 3D bone surface models using Meshlab software (version 1.3.3; Institute of Information Science and Technologies, Pisa, Italy) (Fig. 3). As the glenohumeral rotation center could not be identified in the static images, the origin of the humeral axis was defined as the center of the humeral head $[20,21]$.

\section{Coordinate system}

A coordinate system was designated for each model of the thorax, scapula, humerus, and forearm based on the bony landmarks, as defined by the ISB recommendations [19] (Fig. 4). The left side of the upper extremities was flipped to the right side on the software before designating the coordinate system.

The thoracic coordinate system was defined as follows: The origin was coincident with the deepest point of the sternal notch (incisura jugularis; $I J$ ). The $Y$-axis was defined as the line connecting the midpoint between the xiphoid process (processus xiphoideus) (PX) and the spinal process of the 8th thoracic vertebra (T8) and the midpoint between the IJ and spinal process of the 7th cervical vertebra (C7), pointing upward. The Z-axis was the line perpendicular to the plane formed by the IJ, C7, and midpoint between $\mathrm{PX}$ and $\mathrm{T} 8$, pointing to the right. The $\mathrm{X}$-axis was the common line perpendicular to the $\mathrm{Z}$ - and $\mathrm{Y}$ axis, pointing forward.

The scapular coordinate system was defined as follows: The origin was coincident with the acromial angle (angulus acromialis) (AA). The Z-axis was defined as the line connecting the root of the scapular spine (trigonum spinae scapulae) (TS), and AA, pointing to the right. The $X$-axis was the line perpendicular to the plane formed by the inferior angle (angulus inferior) (AI), AA, and TS, pointing forward. The $\mathrm{Y}$-axis was the common line perpendicular to the $\mathrm{X}$ - and Z-axis, pointing upward.

The humerus coordinate system was defined as follows: The origin was coincident with center of the humeral head $(\mathrm{CH})$ using a sphere fit based on the convex articulating surface above the anatomical neck $[21,22]$. The $\mathrm{Y}$-axis was defined as the line connecting the $\mathrm{CH}$ and the midpoint of the most caudal point on the lateral epicondyle (LE) and medial epicondyle (ME), pointing to $\mathrm{CH}$, and pointing proximally. The Xaxis was the line perpendicular to the plane formed by the $\mathrm{LE}, \mathrm{ME}$, and $\mathrm{CH}$, pointing forward. The Z-axis was the common line perpendicular to the $\mathrm{X}$ - and $\mathrm{Y}$-axis, pointing to the right.

The forearm coordinate system was defined as follows: The origin was coincident with the ulnar styloid (US). The Y-axis was defined as the line connecting the US and the midpoint between the LE and ME, 
pointing proximally. The X-axis was the line perpendicular to the plane through the US, radial styloid (RS), and the midpoint between the LE and ME, pointing forward. The Z-axis was the common line perpendicular to the $\mathrm{X}$ - and $\mathrm{Y}$-axis, pointing to the right.

\section{Calculations of upper extremity rotation angles}

The angular rotations were calculated using the Cardan and Euler angles based on the coordinate system of each bone. The angular rotation of the scapula with regard to the thorax was defined as the scapulothoracic joint angle. The description of the scapulothoracic joint angle was made using the ISB recommended $\mathrm{Y}-\mathrm{X}-\mathrm{Z}$ sequence. The rotation angle was described as the upward/downward rotation about the $\mathrm{X}$-axis, internal/external rotation about the $\mathrm{Y}$-axis, and anterior/posterior tilting about the Z-axis.

The angular rotation of the humerus with regard to the scapula was defined as the glenohumeral joint angle. The ISB recommended $Y-X-Y$ sequence, which has been routinely performed during arm elevation, was not valid for evaluating humeral axial rotation with the arm at the side with a risk of excluding singular positions [23]. Therefore, the rotation sequence had to be changed in agreement with the nogimbal lock incidence and amplitude interpretability of the performed movements [24]. In this study, the description of the glenohumeral joint angle was made using the X-Z-Y sequence, which is reported to have greater clinical applicability than the $Y-X-Y$ sequence [25]. Rotation angle was described as abduction/adduction about the $\mathrm{X}$-axis, internal/external rotation about the $\mathrm{Y}$-axis, and flexion/extension about the Z-axis.

The angular rotation of the forearm with regard to the humerus was defined as the elbow joint angle. The description of the elbow joint angle was made using the ISB recommended Z-X-Y sequence. The rotation angle was described as valgus/varus about the $\mathrm{X}$-axis, pronation/supination about the $\mathrm{Y}$-axis, and flexion/extension about the Z-axis.

\section{Statistical analysis}

SPSS Statistics 26.0.0.0 software (IBM Corp., Armonk, NY, USA) was used for statistical analyses. The intraobserver and interobserver reliabilities for the angular rotation values were assessed by calculating intraclass correlation coefficients (ICCs) based on randomly selected 20 upper extremities. The measurements were made blindly by two observers (ICC model 2,1), and repeated measurements by one observer within a 3-month interval (ICC model 1,1). After determining intra- and interrater reliabilities, the assessments were performed for all subjects by one observer.

The rotation angle data presented a normal distribution using the Shapiro-Wilk test $(P<0.05$ in all rotation angles), and parametric tests were used in the analyses. The differences in angular rotation values between male and female participants were assessed using two-tailed Student's $t$-tests. The correlations in angular rotation values between the right and left upper extremities and the relationships between the angular rotation values of each joint in the $X, Y$, and $Z$ axes were evaluated using Pearson's correlation coefficient. The significance level was set at $P<0.05$ for all analyses. 


\section{Results}

The intraobserver and interobserver correlation coefficients for the angular rotation values exceeded 0.85 for all calculations (Table 1). These results confirmed that the angular rotation values were highly reproducible. 
Table 1

Participant characteristics and three-dimensional angular rotation values of the scapulothoracic, glenohumeral, and elbow joints.

\begin{tabular}{|c|c|c|c|c|c|c|c|}
\hline & & \multicolumn{3}{|c|}{ Mean \pm SD } & \multirow{2}{*}{$\begin{array}{l}\begin{array}{l}\text { Sex } \\
\text { difference }\end{array} \\
\text { P value }\end{array}$} & \multicolumn{2}{|c|}{ ICC (95\% Cl) } \\
\hline & & Total & Male & Female & & Intrarater & Interrater \\
\hline \multirow[t]{4}{*}{ Parameters } & $\begin{array}{l}\text { Age, years } \\
\text { old }\end{array}$ & $\begin{array}{l}44.4 \\
\pm 7.3\end{array}$ & $\begin{array}{l}44.8 \\
\pm 7.6\end{array}$ & $\begin{array}{l}44.2 \pm \\
7.2\end{array}$ & 0.623 & & \\
\hline & Height, cm & $\begin{array}{l}161.6 \\
\pm 8.3\end{array}$ & $\begin{array}{l}170.8 \\
\pm 5.9\end{array}$ & $\begin{array}{l}157.3 \\
\pm 5.3\end{array}$ & $<.001$ ** & & \\
\hline & Weight, kg & $\begin{array}{l}56.3 \\
\pm 9.1\end{array}$ & $\begin{array}{l}64.7 \\
\pm 7.5\end{array}$ & $\begin{array}{l}52.3 \pm \\
6.9\end{array}$ & $<.001$ ** & & \\
\hline & $\mathrm{BMI}, \mathrm{kg} / \mathrm{m}^{2}$ & $\begin{array}{l}21.5 \\
\pm 2.8\end{array}$ & $\begin{array}{l}22.2 \\
\pm 2.7\end{array}$ & $\begin{array}{l}21.2 \pm \\
2.8\end{array}$ & .027 * & & \\
\hline \multirow[t]{3}{*}{$\begin{array}{l}\text { Scapulothoracic } \\
\text { joint }\end{array}$} & $\begin{array}{l}\text { Upward } \\
\text { rotation } \\
\text { (deg) }\end{array}$ & $\begin{array}{l}8.5 \pm \\
5.9\end{array}$ & $\begin{array}{l}8.3 \pm \\
4.8\end{array}$ & $\begin{array}{l}8.6 \pm \\
6.4\end{array}$ & .772 & $\begin{array}{l}0.999 \\
(0.997- \\
1.000)\end{array}$ & $\begin{array}{l}0.994 \\
(0.957- \\
0.999)\end{array}$ \\
\hline & $\begin{array}{l}\text { Internal } \\
\text { rotation } \\
\text { (deg) }\end{array}$ & $\begin{array}{l}28.7 \\
\pm 5.9\end{array}$ & $\begin{array}{l}28.6 \\
\pm 5.7\end{array}$ & $\begin{array}{l}28.8 \pm \\
6.0\end{array}$ & .832 & $\begin{array}{l}0.998 \\
(0.994- \\
1.000)\end{array}$ & $\begin{array}{l}0.999 \\
(0.993- \\
1.000)\end{array}$ \\
\hline & $\begin{array}{l}\text { Anterior } \\
\text { tilting (deg) }\end{array}$ & $\begin{array}{l}7.9 \pm \\
5.2\end{array}$ & $\begin{array}{l}10.0 \\
\pm 5.0\end{array}$ & $\begin{array}{l}7.0 \pm \\
5.0\end{array}$ & $<.001$ ** & $\begin{array}{l}0.996 \\
(0.984- \\
0.999)\end{array}$ & $\begin{array}{l}0.926 \\
(0.630- \\
0.983)\end{array}$ \\
\hline \multirow[t]{3}{*}{$\begin{array}{l}\text { Glenohumeral } \\
\text { joint }\end{array}$} & $\begin{array}{l}\text { Abduction } \\
\text { (deg) }\end{array}$ & $\begin{array}{l}4.4 \pm \\
5.9\end{array}$ & $\begin{array}{l}3.2 \pm \\
5.1\end{array}$ & $\begin{array}{l}4.9 \pm \\
6.2\end{array}$ & .107 & $\begin{array}{l}0.998 \\
(0.994- \\
0.999)\end{array}$ & $\begin{array}{l}0.982 \\
(0.957- \\
0.993)\end{array}$ \\
\hline & $\begin{array}{l}\text { Internal } \\
\text { rotation } \\
\text { (deg) }\end{array}$ & $\begin{array}{l}9.4 \pm \\
12.3\end{array}$ & $\begin{array}{l}8.6 \pm \\
10.9\end{array}$ & $\begin{array}{l}9.7 \pm \\
13.0\end{array}$ & .609 & $\begin{array}{l}0.953 \\
(0.888- \\
0.981)\end{array}$ & $\begin{array}{l}0.953 \\
(0.888- \\
0.981)\end{array}$ \\
\hline & $\begin{array}{l}\text { Flexion } \\
\text { (deg) }\end{array}$ & $\begin{array}{l}-0.3 \pm \\
4.4\end{array}$ & $\begin{array}{l}0.4 \pm \\
4.2\end{array}$ & $\begin{array}{l}-0.7 \pm \\
4.4\end{array}$ & .152 & $\begin{array}{l}0.986 \\
(0.967- \\
0.995)\end{array}$ & $\begin{array}{l}0.923 \\
(0.819- \\
0.969)\end{array}$ \\
\hline \multirow[t]{2}{*}{ Elbow joint } & Valgus (deg) & $\begin{array}{l}9.6 \pm \\
3.7\end{array}$ & $\begin{array}{l}8.1 \pm \\
3.8\end{array}$ & $\begin{array}{l}10.3 \pm \\
3.5\end{array}$ & $<.001 * \star$ & $\begin{array}{l}0.972 \\
(0.931- \\
0.989)\end{array}$ & $\begin{array}{l}0.854 \\
(0.668- \\
0.939)\end{array}$ \\
\hline & $\begin{array}{l}\text { Pronation } \\
\text { (deg) }\end{array}$ & $\begin{array}{l}88.8 \\
\pm \\
14.2\end{array}$ & $\begin{array}{l}87.7 \\
\pm \\
13.1\end{array}$ & $\begin{array}{l}89.4 \pm \\
14.8\end{array}$ & .481 & $\begin{array}{l}0.938 \\
(0.852- \\
0.975)\end{array}$ & $\begin{array}{l}0.938 \\
(0.823- \\
0.976)\end{array}$ \\
\hline
\end{tabular}

SD, standard deviation; ICC, intraclass correlation coefficient; Cl confidence interval $\star P<.05, * * P<.001$ 


\begin{tabular}{|c|c|c|c|c|c|c|}
\hline \multicolumn{4}{|c|}{ Mean \pm SD } & \multirow{2}{*}{$\begin{array}{l}\begin{array}{l}\text { Sex } \\
\text { difference }\end{array} \\
.136\end{array}$} & \multicolumn{2}{|c|}{$\operatorname{ICC}(95 \% \mathrm{Cl})$} \\
\hline $\begin{array}{l}\text { Flexion } \\
\text { (deg) }\end{array}$ & $\begin{array}{l}15.4 \\
\pm 4.2\end{array}$ & $\begin{array}{l}16.2 \\
\pm 4.0\end{array}$ & $\begin{array}{l}15.1 \pm \\
4.2\end{array}$ & & $\begin{array}{l}0.986 \\
(0.967- \\
0.995)\end{array}$ & $\begin{array}{l}0.834 \\
(0.630- \\
0.931)\end{array}$ \\
\hline
\end{tabular}

SD, standard deviation; ICC, intraclass correlation coefficient; Cl confidence interval

$\star \mathrm{P}<.05, * * \mathrm{P}<.001$

The mean angle of the scapulothoracic joint was $8.5^{\circ} \pm 5.9^{\circ}$ of upward rotation, $28.7^{\circ} \pm 5.9^{\circ}$ of internal rotation, and $7.9^{\circ} \pm 5.2^{\circ}$ of anterior inclination. The mean angle of the glenohumeral joint was $4.4^{\circ} \pm 5.9^{\circ}$ of abduction, $9.4^{\circ} \pm 12.3^{\circ}$ of internal rotation, and $0.3^{\circ} \pm 4.4^{\circ}$ of extension. The mean angle of the elbow joint was $9.6^{\circ} \pm 3.7^{\circ}$ of valgus, $88.8^{\circ} \pm 14.3^{\circ}$ of pronation, and $15.4^{\circ} \pm 4.2^{\circ}$ of flexion. The anterior tilt of the scapulothoracic joint was significantly greater in males $(P<0.001)$, and the valgus of the elbow joint was significantly greater in females $(P<0.001)$ (Table 1$)$. The right and left upper extremities' angular rotation values showed strong positive correlations at all angles (Fig. 5).

In the X-axis angular rotation, there was a strong negative correlation between the upward rotation of the scapulothoracic joint and the abduction of the glenohumeral joint $(R=-0.615, P<0.001)$ (Table 2). In the $Y$-axis angular rotation, there was a weak negative correlation between the pronation of the elbow joint and the internal rotation of the glenohumeral joint $(R=-0.353, P<0.001)$ (Table 3$)$. In the Z-axis angular rotation, there was a moderate negative correlation between the anterior tilt of the scapulothoracic joint and flexion of the glenohumeral joint $(R=-0.528, P<0.001)$ (Table 4$)$.

Table 2

Correlation between the angular rotation values of each joint in the X-axis.

\begin{tabular}{|lllll|}
\hline $\begin{array}{l}\mathrm{X} \text {-axis } \\
\text { angular rotation }\end{array}$ & $\begin{array}{l}\text { Pearson's correlation } \\
\text { coefficient }\end{array}$ & $\begin{array}{l}\text { Scapulothoracic } \\
\text { upward rotation }\end{array}$ & $\begin{array}{l}\text { Glenohumeral } \\
\text { abduction }\end{array}$ & $\begin{array}{l}\text { Elbow } \\
\text { valgus }\end{array}$ \\
\hline $\begin{array}{l}\text { Scapulothoracic } \\
\text { upward rotation }\end{array}$ & $\mathrm{R}$ (P value) & $-.615\left(<.001^{\star \star}\right)$ & -.042 \\
$\begin{array}{l}\text { Glenohumeral } \\
\text { abduction }\end{array}$ & $\mathrm{R}$ (P value) & $-.615\left(<.001^{* \star}\right)$ & & -.041 \\
\hline $\begin{array}{l}\text { Elbow } \\
\text { valgus }\end{array}$ & $\mathrm{R}$ (P value) & $-.042(.596)$ & $-.041(.606)$ & \\
\hline$* \star \mathrm{P}<.001$ & & & & \\
\hline
\end{tabular}


Table 3

Correlation between the angular rotation values of each joint in the Y-axis.

\begin{tabular}{|lllll|}
\hline $\begin{array}{l}\text { Y-axis } \\
\text { angular rotation }\end{array}$ & $\begin{array}{l}\text { Pearson's } \\
\text { correlation } \\
\text { coefficient }\end{array}$ & $\begin{array}{l}\text { Scapulothoracic } \\
\text { internal rotation }\end{array}$ & $\begin{array}{l}\text { Glenohumeral } \\
\text { internal rotation }\end{array}$ & $\begin{array}{l}\text { Elbow } \\
\text { pronation }\end{array}$ \\
\hline $\begin{array}{l}\text { Scapulothoracic } \\
\text { internal rotation }\end{array}$ & $\mathrm{R}(\mathrm{P}$ value $)$ & $-.081(.309)$ & -.010 \\
$\begin{array}{l}\text { Glenohumeral } \\
\text { internal rotation }\end{array}$ & $\mathrm{R}(\mathrm{P}$ value $)$ & $-.081(.309)$ & & $-.353(<$ \\
\hline $\begin{array}{l}\text { Elbow } \\
\text { pronation }\end{array}$ & $\mathrm{R}(\mathrm{P}$ value $)$ & $-.010(.900)$ & $-.353\left(<.001^{* \star}\right)$ & \\
\hline$* * \mathrm{P}<.001$ & & & & \\
\hline
\end{tabular}

Table 4

Correlation between the angular rotation values of each joint in the Z-axis.

\begin{tabular}{|lllll|}
\hline $\begin{array}{l}\text { Z-axis } \\
\text { angular rotation }\end{array}$ & $\begin{array}{l}\text { Pearson's correlation } \\
\text { coefficient }\end{array}$ & $\begin{array}{l}\text { Scapulothoracic } \\
\text { anterior tilt }\end{array}$ & $\begin{array}{l}\text { Glenohumeral } \\
\text { flexion }\end{array}$ & $\begin{array}{l}\text { Elbow } \\
\text { flexion }\end{array}$ \\
\hline $\begin{array}{l}\text { Scapulothoracic } \\
\text { anterior tilt }\end{array}$ & $\mathrm{R}(\mathrm{P}$ value $)$ & $-.528(<$ & -.093 \\
\hline $\begin{array}{l}\text { Glenohumeral } \\
\text { flexion }\end{array}$ & $\mathrm{R}(\mathrm{P}$ value $)$ & $\left.-.5281^{* \star}\right)$ & $-.284\left(<.001^{* \star}\right)$ \\
\hline $\begin{array}{l}\text { Elbow } \\
\text { flexion }\end{array}$ & $\mathrm{R}(\mathrm{P}$ value $)$ & & $\left..001^{* *}\right)$ \\
\hline$\star * \mathrm{P}<.001$ & & $-.093(.247)$ & $-.284(<$ & \\
\hline
\end{tabular}

\section{Discussion}

The present study revealed the 3D alignment of the upper extremities in the standing neutral position in healthy subjects using an upright CT scanner. The normal values of the rotation of upper extremity joints in the standing neutral position had not been clarified yet, and our results could be useful in evaluating and treating pathological abnormalities in the upper extremities. The angular rotation values in the right and left upper extremities were strongly correlated and generally consistent with one another. When diagnosing an altered joint position [26] or deciding a treatment plan for malunion deformities [27, 28], 
contralateral intact extremity is often referenced. The present results support the assumption that the left and right joint angles are comparable and suggest that it is reasonable to use the intact joint angle as a reference.

Significant sex differences in angular rotation values were observed in the anterior tilt of the scapulothoracic joint and in the valgus of the elbow joint. There are sex differences in the composition and function of skeletal muscle [29], and the muscles that stabilize the scapula to the thorax, namely, the rhomboids, levator scapulae, and trapezius, are stronger in males than in females and can be presumed to support the scapula in an upward direction [30,31]. Valgus of the elbow joint, which is called the carrying angle, was reported to vary between sex [32,33], and the present results are consistent with the literature. Concerning the age of the epiphyseal closure around the elbow, there is an increase in the carrying angle until 15 years age. The sex difference in the carrying angle was reported to depend on the joint laxity or the onset of adolescence [34,35].

Interactions to maintain balance have been reported in the spine and lower extremities $[10,35,36]$, whereas none have been reported in the upper extremities. In this study, we found that these interactions are also observed in the neutral position of the upper extremities. As pelvic tilt correlates with knee flexion to keep the sagittal balance in the neutral position of the lower extremity, internal rotation of the glenohumeral joint correlates with the pronation of the elbow joint to keep the axial balance in the upper extremities. When the internal rotation angle of the glenohumeral joint was decreased, there was a compensatory increase in the internal rotation of the glenohumeral joint in order to align the palms with the body trunk (Fig. 6). Therefore, in shoulder X-ray imaging, which is mainly taken in a standing neutral position, the positional relationship between the scapula and humerus is often different even if the images are taken in the same posture [6].

These interactions were also observed in the upward rotation of the scapulothoracic joint and adduction of the glenohumeral joint. In the neutral position of the upper extremities with the arms resting at the side, the glenohumeral joint is relatively adducted when the scapula rotates upward. The abduction angle of the glenohumeral joint changes depending on the individual alterations in the resting position of the scapula.

The anterior tilt of the scapulothoracic joint correlates with the extension of the glenohumeral joint. This interaction is consistent with the shoulder girdle motion studies [4,37], which indicate an increase in the posterior tilt of the scapulothoracic joint conjunction with an increase in the flexion of the glenohumeral joint.

This study had limitations. First, the postural sway in a standing neutral position was not evaluated. However, volunteers were positioned along the pole to avoid any effect of posture. We made sure that the volunteers were in the same position and excluded those with scoliosis. Second, asymptomatic scapula dyskinesis and humeral head retroversion were not evaluated. Although these factors might affect the results of this study, scapular positional and humeral head anatomical variations have been reported to exist among healthy subjects $[11,38,39]$, and these differences were included as normal joint angular 
rotation values. It is expected that future studies will clarify the role of alignment in upper extremity disorders, which will be useful for diagnosis, treatment, and functional assessment.

\section{Conclusions}

This study evaluated the 3D angular rotation of upper extremity joints in the standing neutral position using an upright CT scanner. Angular rotation values may provide important clues for evaluating and understanding the function of upper extremity alignment.

\section{Abbreviations}

AA: acromial angle (angulus acromialis)

Al: inferior angle (angulus inferior)

BMI: body mass index

$\mathrm{CH}$ : center of the humeral head

CT: computed tomography

C7: spinal process of the 7th cervical vertebra

DICOM: Digital Imaging and Communication in Medicine

ICCs: intraclass correlation coefficients

IJ: sternal notch (incisura jugularis)

ISB: International Society of Biomechanics

LE: lateral epicondyle

ME: medial epicondyle

PX: xiphoid process (processus xiphoideus)

RS: radial styloid

STL: Standard Triangulated Language

TS: root of the scapular spine (trigonum spinae scapulae)

T8: spinal process of the 8th thoracic vertebra

US: ulnar styloid 


\section{Declarations}

\section{Ethics approval and consent to participate}

This prospective study was approved by the institutional review board of Keio University School of Medicine, and written consent was obtained from all the participants (study protocol: \#20160384).

\section{Consent for publication}

Not applicable.

\section{Availability of data and materials}

The datasets used and/or analyzed during the current study are available from the corresponding author on reasonable request.

\section{Competing interests}

Masahiro Jinzaki received a grant from Canon Medical Systems, which loaned the upright CT device to Keio University. The funder was not involved in the design of the study; the collection, analysis, or interpretation of the data; or the writing of the manuscript. The other authors declare that they have no conflicts of interest.

\section{Funding}

This study was supported by Japan Society for the Promotion of Science (JSPS) KAKENHI (grant number JP17H04266, JP17K16482, and JP20K08056), Uehara Memorial Foundation, and Canon Medical Systems (Otawara, Japan).

\section{Authors' contributions}

Y. Yoshida: concept/design, data analysis, drafting of the manuscript, critical revision of the manuscript, approval of the article. N. Matsumura: concept/design, critical revision of the manuscript, approval of the article. Y. Yamada: data collection, critical revision of the manuscript, approval of the article. S. Hiraga: data analysis, approval of the article. K. Ishii: data analysis, validation, approval of the article. S. Oki: data analysis, approval of the article. Y. Yokoyama: data collection, approval of the article. M. Yamada: data collection, approval of the article. M. Nakamura: supervision, approval of the article. T. Nagura: 
supervision, critical revision of the manuscript, approval of the article. M. Jinzaki: developed the project, supervision, approval of the article.

\section{Acknowledgements}

The authors would like to thank Sho Watanabe, a medical student at Keio University, for helping with data analysis.

\section{References}

1. Czaprowski D, Stoliński $\measuredangle$, Tyrakowski M, Kozinoga M, Kotwicki T. Non-structural misalignments of body posture in the sagittal plane. Scoliosis Spinal Disord. 2018;13:6.

2. Janssen MM, Kouwenhoven JW, Schlösser TP, Viergever MA, Bartels LW, Castelein RM, et al. Analysis of preexistent vertebral rotation in the normal infantile, juvenile, and adolescent spine. Spine. 2011;36:E486-91.

3. Coley B, Jolles BM, Farron A, Aminian K. Arm position during daily activity. Gait Posture. 2008;28:581-7.

4. Ludewig PM, Phadke V, Braman JP, Hassett DR, Cieminski CJ, LaPrade RF. Motion of the shoulder complex during multiplanar humeral elevation. J Bone Joint Surg Am. 2009;91:378-89.

5. Warner MB, Chappell PH, Stokes MJ. Measurement of dynamic scapular kinematics using an acromion marker cluster to minimize skin movement artifact. J Vis Exp. 2015;96:e51717.

6. Goud A, Segal D, Hedayati P, Pan JJ, Weissman BN. Radiographic evaluation of the shoulder. Eur J Radiol. 2008;68:2-15.

7. Hengg C, Mayrhofer P, Euler S, Wambacher M, Blauth M, Kralinger F. The relevance of neutral arm positioning for true ap-view X-ray to provide true projection of the humeral head shaft angle. Arch Orthop Trauma Surg. 2016;136:213-21.

8. Li J, Zhang Y, Zhang N, Xv ZK, Li H, Chen G, et al. Clinical outcome of laminoplasty for cervical ossification of the posterior longitudinal ligament with K-line (-) in the neck neutral position but K-line $(+)$ in the neck extension position: A retrospective observational study. Med (Baltim). 2017;96:e6964.

9. Brown MJC, Deakin AH, Picard F, Riches PE, Clarke JV. Lower limb alignment becomes more varus and hyperextended from supine to bipedal stance in asymptomatic, osteoarthritic and prosthetic neutral or varus knees. Knee Surg Sports Traumatol Arthrosc. 2019;27:1635-41.

10. Gong H, Sun L, Yang R, Pang J, Chen B, Qi R, et al. Changes of upright body posture in the sagittal plane of men and women occurring with aging - a cross sectional study. BMC Geriatr. 2019;19:71.

11. Kibler WB, Uhl TL, Maddux JW, Brooks PV, Zeller B, McMullen J. Qualitative clinical evaluation of scapular dysfunction: a reliability study. J Shoulder Elbow Surg. 2002;11:550-6.

12. Ohlendorf D, Adjami F, Scharnweber B, Schulze J, Ackermann H, Oremek GM, et al. Standard values of the upper body posture in male adults. Adv Clin Exp Med. 2018;27:1521-8. 
13. Hasegawa K, Okamoto M, Hatsushikano S, Shimoda H, Ono M, Homma T, et al. Standing sagittal alignment of the whole axial skeleton with reference to the gravity line in humans. J Anat. 2017;230:619-30.

14. Jinzaki M, Yamada Y, Nagura T, Nakahara T, Yokoyama Y, Narita K, et al. Development of upright computed tomography with area detector for whole-body scans: phantom study, efficacy on workflow, effect of gravity on human body, and potential clinical impact. Invest Radiol. 2020;55:7383.

15. Yamada Y, Yamada M, Chubachi S, Yokoyama Y, Matsuoka S, Tanabe A, et al. Comparison of inspiratory and expiratory lung and lobe volumes among supine, standing, and sitting positions using conventional and upright CT. Sci Rep. 2020;10:16203.

16. Yamada Y, Yamada M, Yokoyama Y, Tanabe A, Matsuoka S, Niijima Y, et al. Differences in lung and lobe volumes between supine and standing positions scanned with conventional and newly developed 320-detector-row upright CT: intra-individual comparison. Respiration. 2020;99:598-605.

17. Yamada $Y$, Jinzaki M, Hosokawa T, Tanami Y, Sugiura $H, A$ be $T$, et al. Dose reduction in chest CT: comparison of the adaptive iterative dose reduction 3D, adaptive iterative dose reduction, and filtered back projection reconstruction techniques. Eur J Radiol. 2012;81:4185-95.

18. Wei D, Jacobs S, Modla S, Zhang S, Young CL, Cirino R, et al. High-resolution three-dimensional reconstruction of a whole yeast cell using focused-ion beam scanning electron microscopy. Biotechniques. 2012;53:41-8.

19. Yoshida Y, Matsumura N, Yamada Y, Yamada M, Yokoyama Y, Matsumoto M, et al. Evaluation of three-dimensional acromiohumeral distance in the standing position and comparison with its conventional measuring methods. J Orthop Surg Res. 2020;15:436.

20. Wu G, van der Helm FC, Veeger HE, Makhsous M, Van Roy P, Anglin C, et al. ISB recommendation on definitions of joint coordinate systems of various joints for the reporting of human joint motion-Part II: Shoulder, elbow, wrist and hand. J Biomech. 2005;38:981-92.

21. DeLude JA, Bicknell RT, MacKenzie GA, Ferreira LM, Dunning CE, King GJ, et al. An anthropometric study of the bilateral anatomy of the humerus. J Shoulder Elbow Surg. 2007;16:477-83.

22. Drew AJ, Tashjian RZ, Henninger HB, Bachus KN. Sex and laterality differences in medullary humerus morphology. Anat Rec (Hoboken). 2019;302:1709-17.

23. Doorenbosch CA, Harlaar J, Veeger DH. The globe system: an unambiguous description of shoulder positions in daily life movements. J Rehabil Res Dev. 2003;40:147-55.

24. Senk M, Chèze L. Rotation sequence as an important factor in shoulder kinematics. Clin Biomech (Bristol Avon). 2006;21:3-8.

25. Phadke V, Braman JP, LaPrade RF, Ludewig PM. Comparison of glenohumeral motion using different rotation sequences. J Biomech. 2011;44:700-5.

26. Kibler WB, Sciascia A, Wilkes T. Scapular dyskinesis and its relation to shoulder injury. J Am Acad Orthop Surg. 2012;20:364-72. 
27. Park S, Kim E. Estimation of carrying angle based on CT images in preoperative surgical planning for cubitus deformities. Acta Med Okayama. 2009;63:359-65.

28. Takeyasu Y, Oka K, Miyake J, Kataoka T, Moritomo H, Murase T. Preoperative, computer simulationbased, three-dimensional corrective osteotomy for cubitus varus deformity with use of a customdesigned surgical device. J Bone Joint Surg Am. 2013;95:e173.

29. Haizlip KM, Harrison BC, Leinwand LA. Sex-based differences in skeletal muscle kinetics and fibertype composition. Physiology (Bethesda). 2015;30:30-9.

30. Kibler WB. The role of the scapula in athletic shoulder function. Am J Sports Med. 1998;26:325-37.

31. Matsumura N, Yamada Y, Oki S, Yoshida Y, Yokoyama Y, Yamada M, et al. Three-dimensional alignment changes of the shoulder girdle between the supine and standing positions. J Orthop Surg Res. 2020;15:411.

32. Potter HP. The obliquity of the arm of the female in extension. The relation of the forearm with the upper arm in flexion. J Anat Physiol. 1895;29:488-91.

33. Paraskevas G, Papadopoulos A, Papaziogas B, Spanidou S, Argiriadou H, Gigis J. Study of the carrying angle of the human elbow joint in full extension: a morphometric analysis. Surg Radiol Anat. 2004;26:19-23.

34. Beals RK. The normal carrying angle of the elbow. A radiographic study of 422 patients. Clin Orthop Relat Res. 1976;119:194-6.

35. Obeid I, Hauger O, Aunoble S, Bourghli A, Pellet N, Vital JM. Global analysis of sagittal spinal alignment in major deformities: correlation between lack of lumbar lordosis and flexion of the knee. Eur Spine J. 2011;20:681-5.

36. Barrey C, Roussouly P, Le Huec JC, D'Acunzi G, Perrin G. Compensatory mechanisms contributing to keep the sagittal balance of the spine. Eur Spine J. 2013;22:834-41.

37. Lee B, Kim D, Jang Y, Jin H. Three-dimensional in vivo scapular kinematics and scapulohumeral rhythm: a comparison between active and passive motion. J Shoulder Elbow Surg. 2020;29:185-94.

38. Burkhart SS, Morgan CD, Kibler WB. The disabled throwing shoulder: spectrum of pathology Part III: The SICK scapula, scapular dyskinesis, the kinetic chain, and rehabilitation. Arthroscopy. 2003;19:641-61.

39. Matsumura N, Oki S, Ogawa K, Iwamoto T, Ochi K, Sato K, et al. Three-dimensional anthropometric analysis of the glenohumeral joint in a normal Japanese population. J Shoulder Elbow Surg. 2016;25:493-501.

\section{Figures}




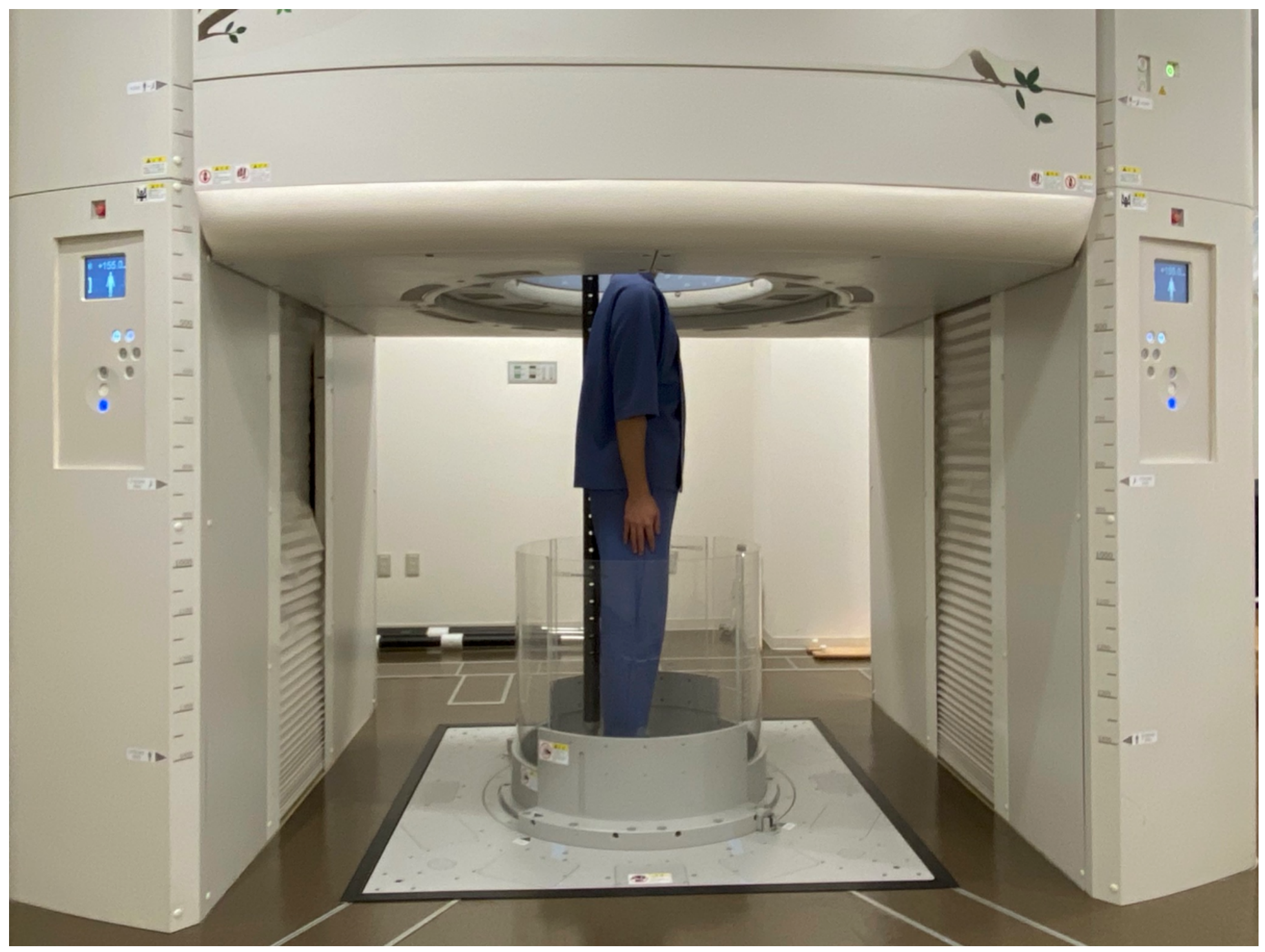

\section{Figure 1}

Computed tomography (CT) images of the bilateral upper extremities were obtained in the standing neutral position using an upright CT scanner. 


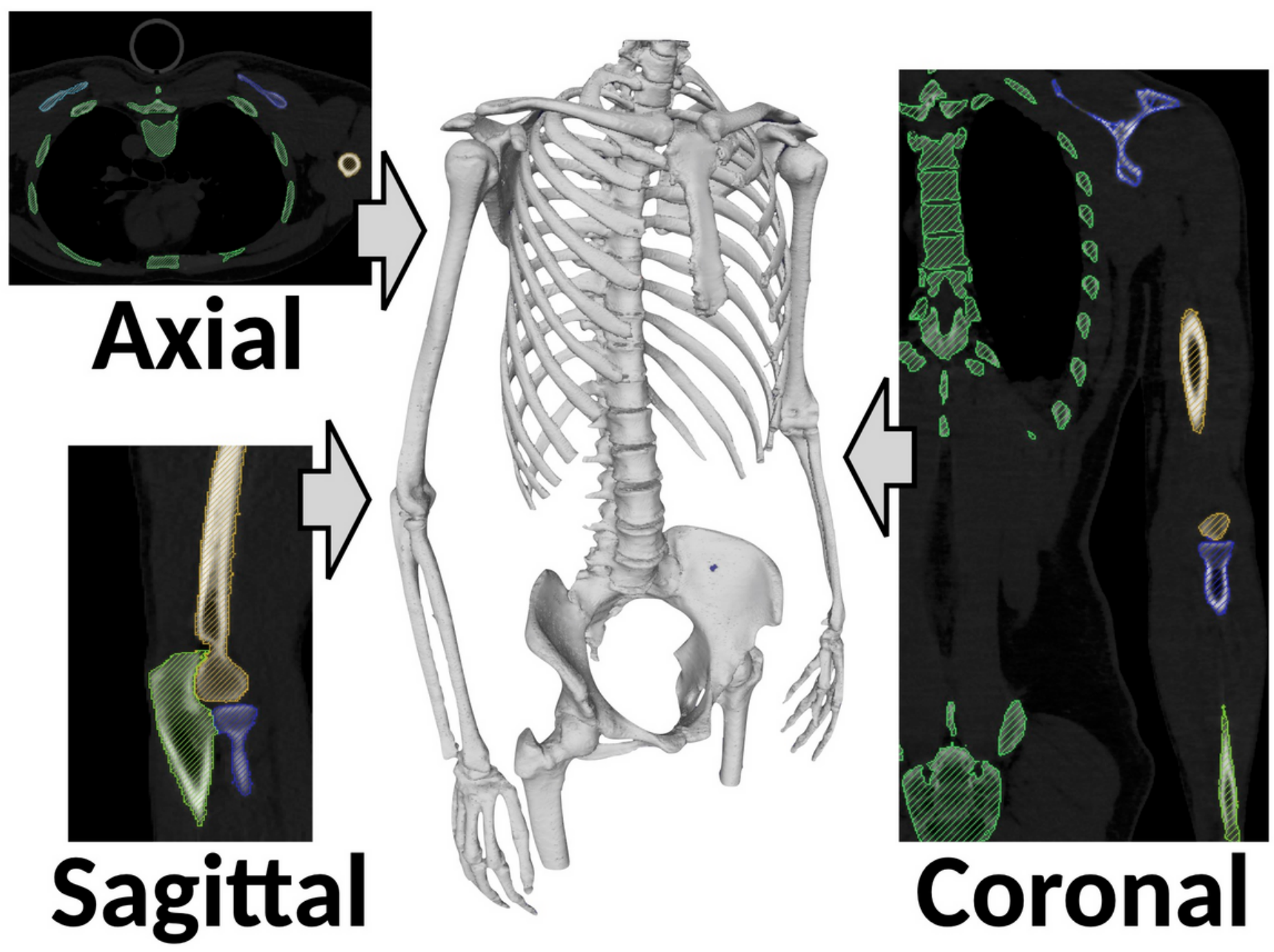

Figure 2

Creating three-dimensional surface models of the body and upper extremities from Digital Imaging and Communication in Medicine data using AVIZO software. Bone part segmentation was performed to observe three views of multiplanar reformatting. 

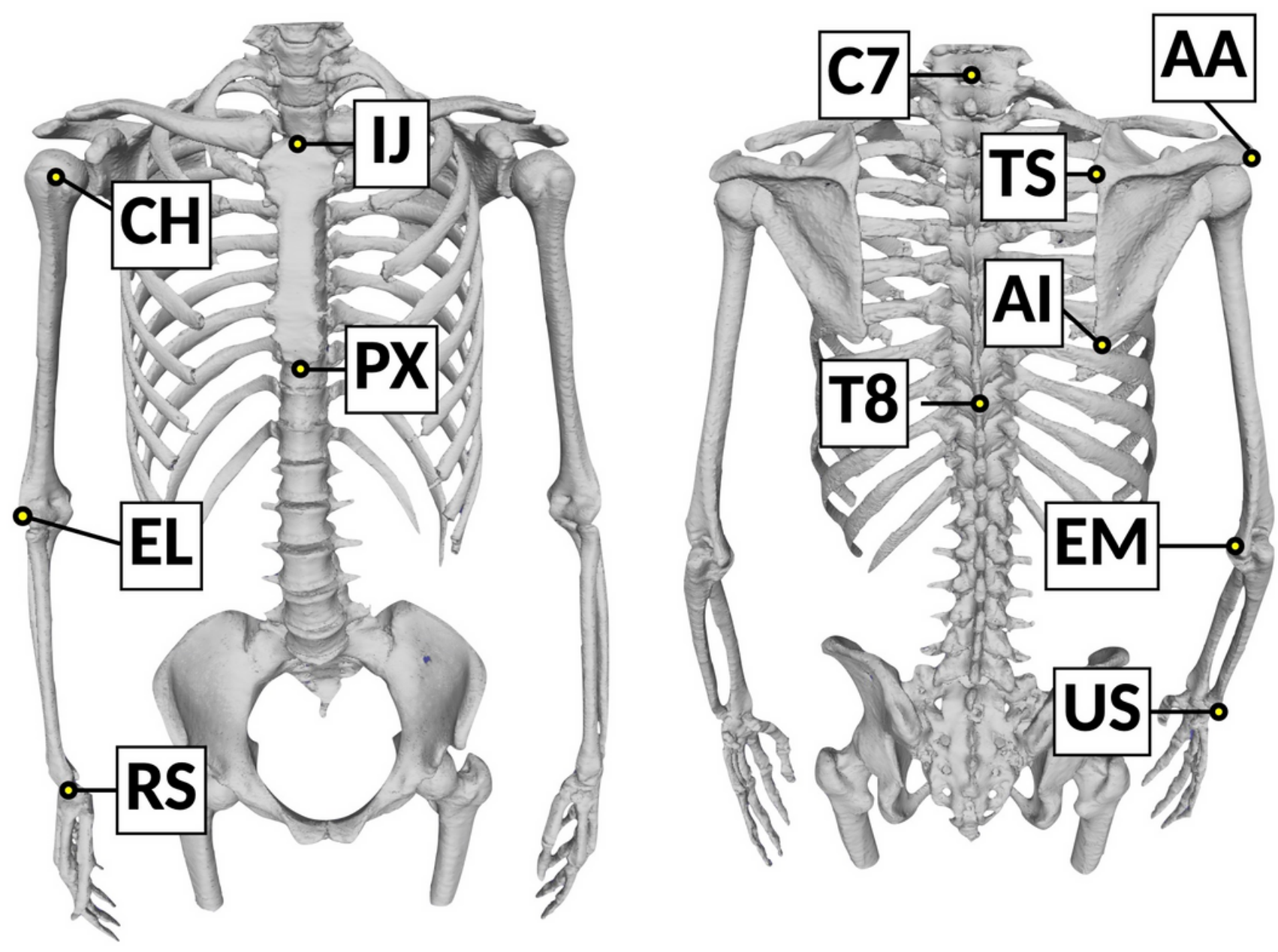

Figure 3

Bony landmarks to create coordinate system of each bone.

IJ, sternal notch (incisura jugularis); PX, xiphoid process (processus xiphoideus); C7, spinal process of the 7th cervical vertebra; T8, spinal process of the 8th thoracic vertebra; AA, acromial angle (angulus acromialis); TS, root of the scapular spine (trigonum spinae scapulae); Al, inferior angle (angulus inferior); $\mathrm{CH}$, center of the humeral head; LE, lateral epicondyle; ME, medial epicondyle; RS, radial styloid; US, ulnar styloid. 


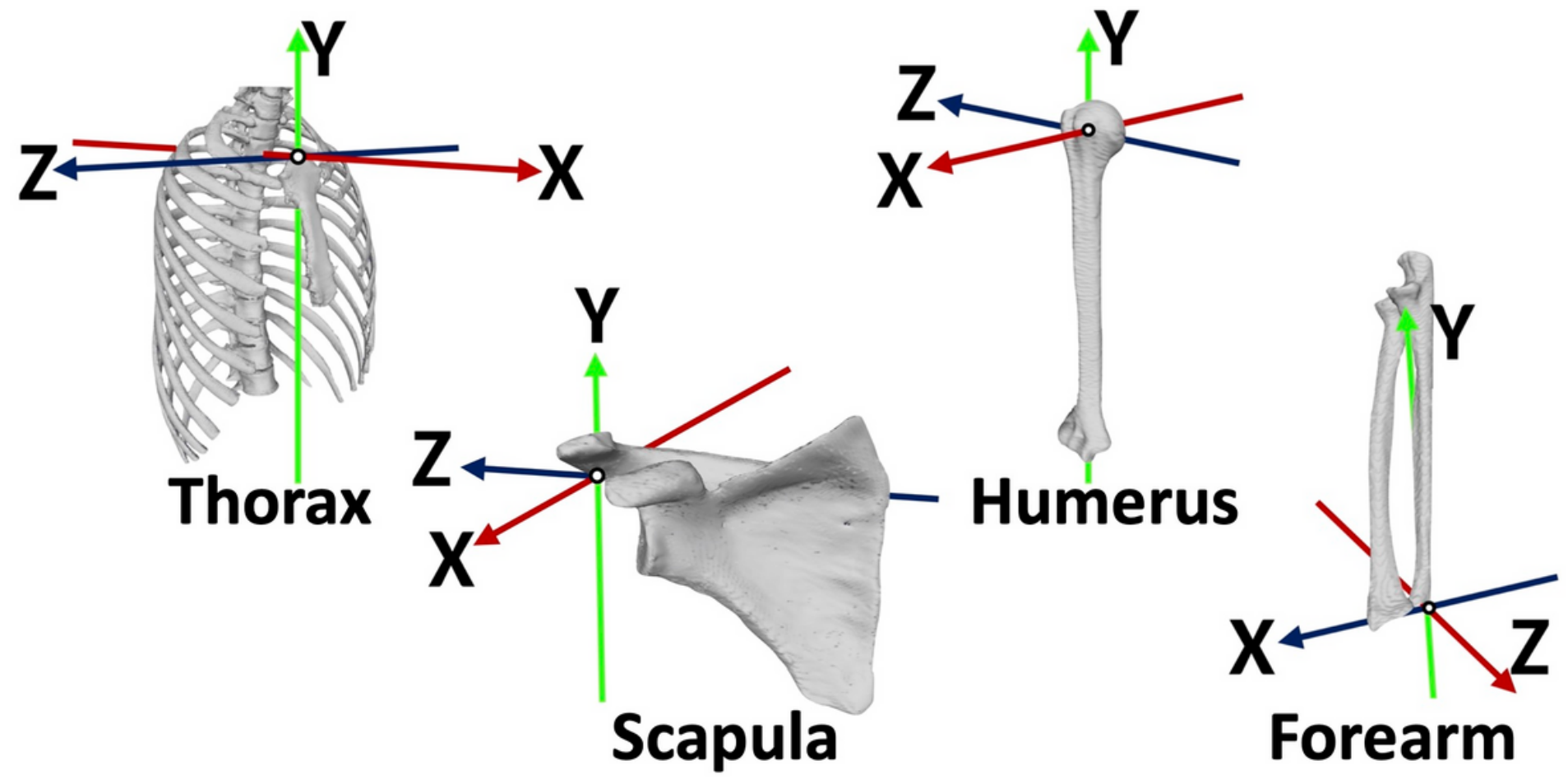

Figure 4

The three-dimensional coordinate system of the thorax, scapula, humerus, and forearm.
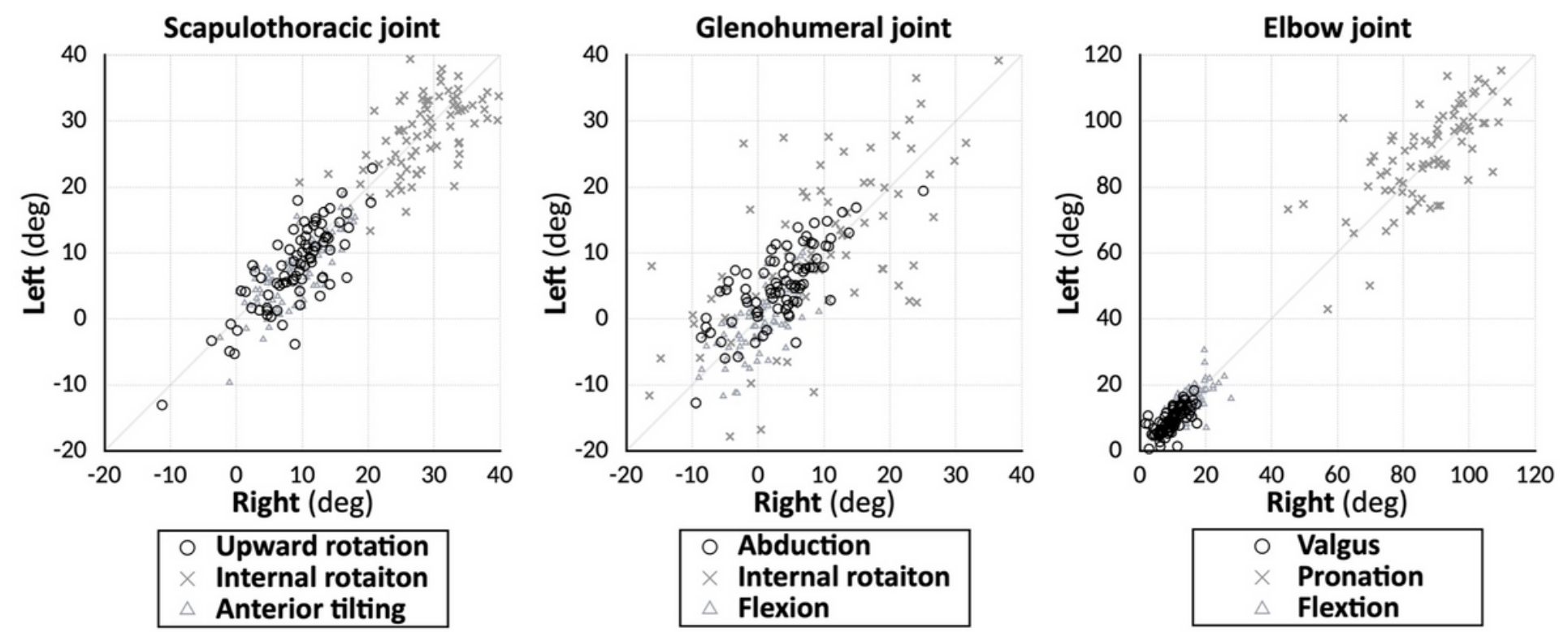

Figure 5 
Linear regression plots of angular rotation values compared between the right and left upper extremities. Values showed a strong positive correlation in all angles (scapulothoracic joint: upward rotation $R=$ $0.798, P<0.001$; internal rotation $R=0.548, P<0.001$; anterior tilt $R=0.778, P<0.001$; glenohumeral joint: abduction $R=0.739, P<0.001$; internal rotation $R=0.595$; $P<0.001$; flexion $R=0.653, P<0.001$. elbow joint: valgus $R=0.688, P<0.001$; pronation $R=0.677, P<0.001$; and flexion $R=0.603, P<0.001$ ).

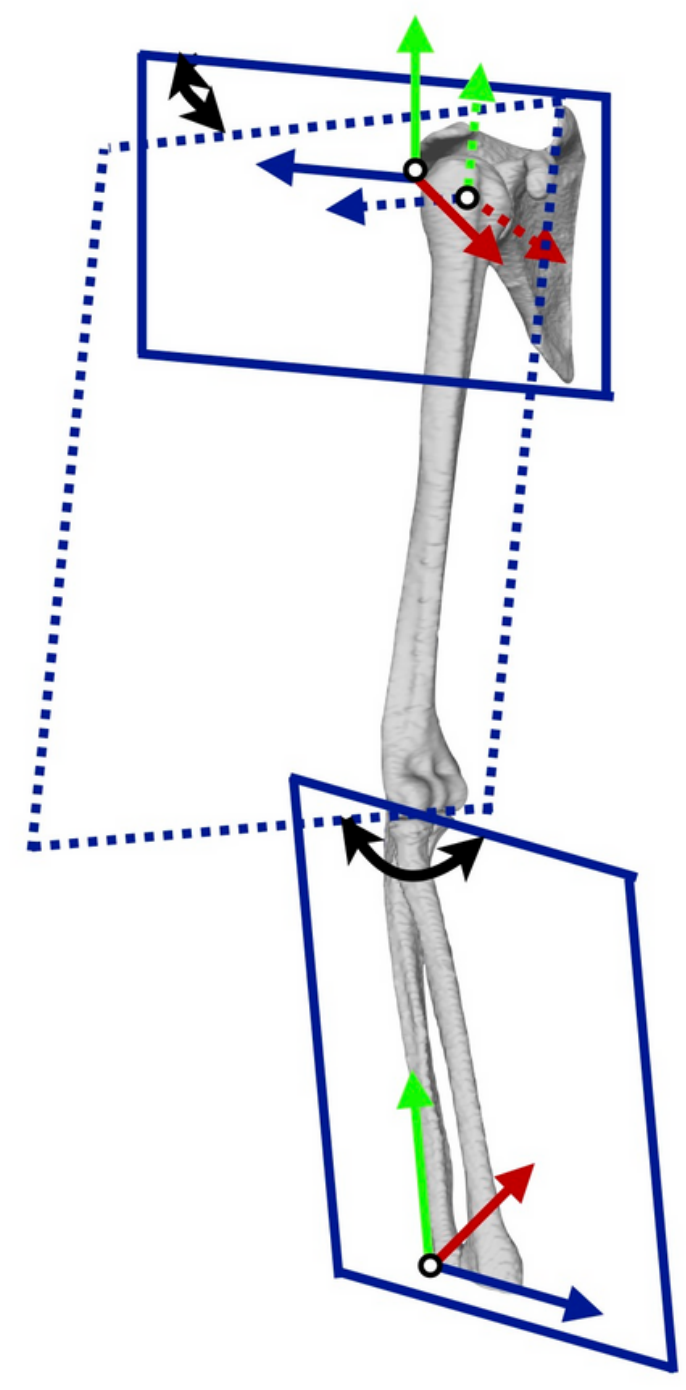

Figure 6

Angular rotation between the pronation of the elbow joint and internal rotation of the glenohumeral joint. There was an interaction for greater pronation to become external rotation. 